World Lumen Congress 2021 | May 26-30, 2021 |

lasi, Romania

\title{
Doping Control in the Republic of Moldova: Specific Features
}

\author{
Ecaterina LUNGU
}

https://doi.org/10.18662/wlc2021/36

How to cite: Lungu, E. (2021). Doping Control in the Republic of Moldova: Specific Features. In A. Sandu (vol. ed.), Lumen Proceedings: Vol. 17 World Lumen Congress 2021 (pp. 372-378). Iasi, Romania: LUMEN Publishing House. https://doi.org/10.18662/wlc2021/36 


\title{
Doping Control in the Republic of Moldova: Specific Features
}

\author{
Ecaterina LUNGU1
}

\begin{abstract}
Recently, there has been a strong effort regarding all sports organizations in order to reduce the universality and frequency of doping in sport. However, the efficacy of current strategies to fight against doping might be improved by using anti-doping polices adjusted to the features of doping in each sport. Contemporary sports activity is regarded as a complex phenomenon that involves both physical components, as well as a variety of medical, legal or economic aspects. In recent times, sport worldwide is marked by severe discussions on doping and its effects. In this context, athletes and team members must know the facts that may empower violations of anti-doping legislation and regulations on the doping control procedure. The acquisition of these legal and medical rules will motivate the development of sports, with the effect of preventing risks represented by the doping phenomenon.
\end{abstract}

Keywords: Doping control, sport, survey, responsibility, anti-doping organization.

\section{Introduction}

Sport is meant to develop the human spirit, body and mind, but the values of sport are based on ethics, fair play, honesty, health, performance, education, character, joy, team spirit, devotion or courage. At the same time, sports activity emphasizes respect for the person of the athlete, but also respect for laws and regulations. Unfortunately, doping is no longer a unitary or individual action of an athlete, but has developed into a dangerous phenomenon, with disastrous consequences for athletes, coaches, doctors or authorities. Under these conditions, it is crucial to take firm positions and adopt effective regulations that prevent cases of doping in sports, but also to combat illicit activities, which affect, in the most direct way, the national or world sports movement.

\section{Research methodology and organization}

The normative-legislative, methodological and empirical basis of the paper

\footnotetext{
${ }^{1} \mathrm{PhD}$ student, State University of Physical Education and Sport, Chisinau, Republic of Moldova. Email:kathya@mail.ru
} 
represents the international conventions against doping in sports, the world antidoping code, international standards for testing or laboratories, but also national legislation in the field of sports and preventing and combating doping in sports as well. The lack for various reasons of the national specialized sources regarding some aspects of the topic was the main factor of studying the subject. The elaboration of the paper was based on the application of the historical analysis method, the logical analysis method (deductive, inductive, generalization analysis), the comparative and systematic analysis method, as well as the prospective method, used to predict the evolution of the doping situation in Moldova.

\section{The results and their interpretation}

According to national and international doping practices (Parliament of Romania, 2006; Parliament of Romania, 2012) a number of facts are recognized in sports activity that constitute violations of anti-doping legislation:

- the presence of a prohibited substance, its metabolites or its markers in an athlete's body;

- the use or attempt to use a prohibited substance or methods. The use of prohibited substances or methods may be achieved by the application, ingestion, injection or consumption by any means of any prohibited substance or method.

- refusing to take a biological sample after notification, in accordance with the anti-doping rules in force, or unjustifiably evading the taking of a biological sample or avoiding the taking of such a sample by any means;

- breach of the obligations regarding the availability of athletes for doping control outside the competition, including non-compliance by athletes with the obligation to provide information on their location, as well as failure to attend controls considered to be organized on the basis of reasonable rules;

- falsification or attempted falsification of any element of the doping control process (Parliament of Romania, 2012).

At the same time, they are associated with violations of anti-doping legislation and the possession or trafficking of prohibited substances or methods, and if these substances are included in the list of narcotics or psychotropic substances, the contravention or criminal liability is also provided.

In most cases, the violation of anti-doping rules concerns the person who systematically or professionally practices a sport. However, for the administration or attempted administration of a prohibited substance or method to an athlete or the assistance, encouragement, contribution, incitement, concealment or any other form of complicity involving an infringement or an attempted violation of anti-doping rules involves the prosecution of the athlete's assistant staff. The quality of assistants is held by any coach, instructor, manager, sports agent, team management staff, official, any medical or paramedical staff and any person who advises the athlete who participates or is preparing to participate in a sports competition.

In addition to these actions, the prescription or administration of prohibited substances according to the list of the World Anti-Doping Agency, except for those 
for which exemption for therapeutic use has been granted, constitutes a medical offense and is punished according to the legislation in force and notified to the National Anti-Doping Agency League of Physicians of the Republic of Moldova.

The doping cases recently discovered on the international arena demonstrate complicity not only of the athlete's assistant staff, but also of the representatives of the government institutions. In this context, the commission of the act by a person who has, according to this law, attributions in preventing and combating doping in sports or by a person who performs a function involving the exercise of public authority, and the act was committed in the exercise of this function, are considered aggravating circumstances.

At the same time, in the case of offering, prescribing, administering prohibited substances or methods to a minor athlete, the maximum special term of penalties is increased by one third.

In order to prevent and counteract these facts, as well as in order to combat the phenomenon of doping in sports, the National Anti-Doping Agency (hereinafter - NADA) was established in the Republic of Moldova. In accordance with international commitments, NADA publishes annually the list of prohibited substances and methods, in accordance with the list of the World Anti-Doping Agency (hereinafter - WADA) and the specifications operated by the Eastern European Regional Anti-Doping Organization (hereinafter - EERADO). Within the same process, NADA publishes and updates annually, in collaboration with the Ministry of Health, the list of pharmaceutical preparations authorized and marketed in the Republic of Moldova, which contain doping substances.

NADA is responsible for publishing this list in the Official Gazette of the Republic of Moldova and is obliged to inform in writing all decision-makers in the field of sport on any change in the prohibited list (The Government of Romania, 2003). From the moment of official publication it is assumed that all athletes should know about the new substances, which should not be administered to athletes, and they cannot refer to the ignorance of these prescriptions, in case of detection of positive results in doping control.

In this context, the responsibility for the medical treatment applied to athletes is also placed on doctors and nurses, who must:

- not recommend, prescribe or administer drugs containing prohibited substances when they can be replaced by others that do not contain such substances, except the terrific cases;

- not to recommend, prescribe or cooperate in the use of prohibited methods that are included in the prohibited list;

- to prevent the use of prohibited substances and / or methods by athletes;

- to inform the responsible national athletes and sports federations on the medication administered for therapeutic purposes, its composition and the effects on the body.

In addition to the function of drawing up lists of prohibited substances and methods and informing athletes about their existence, NADA benefits by another legal instrument, which is intended to prevent and combat the use of prohibited 
substances and / or methods, namely doping control.

The doping control tool is a complex process, which includes testing planning, collecting and transporting biological samples, laboratory analysis, results management, hearings and appeals. According to its competencies, NADA organizes and performs two types of doping controls:

- doping control in competition - doping control in which athletes are selected to be tested in connection with participation in a particular competition, and

- doping control out of competition - any doping control that it is not achieved in the competition.

In the case of international competitions organized in the Republic of Moldova, the competence of NADA is limited, given that the controls are performed by international sports federations.

Doping control, in competition and out of competition, is performed according to the annual national testing plan, in compliance with the provisions of the International Testing Standard issued by WADA. As an exception, in case of emergency notifications, the Director General of NADA may order an unplanned doping control. The procedure for carrying out the doping control is regulated by the methodological norms regarding the organization and realization of the doping control, which are elaborated by NADA in accordance with the provisions of the World Anti-Doping Code and the International Standard for testing.

Despite the fact that doping control is carried out by NADA on its own initiative, however, a control can be initiated at the request of the Ministry of Youth and Sports, the National Olympic and Sports Committee, national sports federations, professional clubs or leagues, other organizers of national sports events, anti-doping organizations of other states, international anti-doping organizations or other international sports structures.

Given the complex process in which doping control is performed, its costs are borne by the sponsor of the control.

Both international regulations and national regulations oblige the athlete participating in a sports competition to undergo a doping test. In general, doping testing is part of the process of conducting doping control that involves planning tests, collecting biological samples, handling and transporting biological samples to the laboratory.

In parallel with the planned tests, NADA can also perform target tests. These involve selecting athletes for doping testing in which certain specially chosen athletes or groups of athletes are selected based on specific rules for performing tests at a given time. Target and out-of-competition tests may be performed at any time, without prior notice, at the nearest doping control station, at the athlete's accommodation during the training period, at all places where physical and sporting activities take place or at the athlete's domicile. During the doping control without prior notice, the athlete is accompanied at all times, from the moment of announcement until the biological sample is taken.

In addition, the national record can be approved only after the doping test 
of the athlete in question, immediately after his registration. This measure is imposed by the fact of the desire of the athletes to acquire the competitive primacy and to break the existing records.

The doping testing process is complex and must be performed with the utmost care and caution, in order to avoid procedural challenges. In this sense, the doping control officers who graduated the professional training and improvement courses organized by NADA and obtained a certificate from WADA have the responsibility of managing the biological sampling session on the spot, and NADA is responsible on the collection and transport of biological samples to the laboratory.

Doping testing in competition is performed in appropriate spaces called doping control station, organized according to methodological rules on the organization and conduct of doping control, and sports base administrators are required to arrange appropriate spaces for doping control and collection of any biological material as biological evidence.

During the test, the doping control officer notifies the selected athlete in writing and asks him to sign the doping control invitation. From the moment of notification, the athlete is under the permanent supervision of the officer. The doping test includes the following steps:

- accompanying to the doping control station;

- hydrating the athlete with soft drinks;

- selection of the biological sample collection container;

- issuing a urine sample;

- separation of the biological sample into two bottles;

- sealing the bottles and establishing the sample code in the control act;

- checking the acidity and concentration of the sample to determine its quality;

- issuing additional evidence, as appropriate;

- finding data on the use of prohibited substances and / or methods;

- signing the control act by the athlete and the doping control officer and sending a copy to the athlete;

- transportation of samples to the authorized laboratory.

The analysis of biological samples is performed in a laboratory accredited by WADA according to international standards, and the result of the laboratory analysis is issued in the form of an analysis bulletin that is communicated to NADA.

The finding of a positive result, which confirms the presence in a biological sample of a prohibited substance, its metabolites or markers or other evidence of the use of prohibited methods, obliges NADA to verify whether an exemption for therapeutic use has been granted or whether there is a suspicion of violation of the provisions of the International Standard for Testing or the International Standard for Laboratories of WADA, which would invalidate the validity of the positive result found. The lack of the mentioned conditions allows NADA to inform the athlete about the found result, violations and the right to request the counter-expertise.

The laboratory authorized to analyze the biological samples may issue an 
analysis bulletin with atypical results. In this situation, NADA verifies whether an exemption has been granted for therapeutic use or whether there is a suspicion of a violation of the provisions of the International Standard for Testing or the International Standard for Laboratories, which would invalidate the validity of the atypical result found. The lack of the mentioned conditions allows it to carry out the subsequent investigations necessary to establish whether or not the atypical result will be submitted as a positive result, with the information of the athlete and other interested persons.

As mentioned above, doping control extends to other facts, the finding of which does not involve the analysis of biological samples. In this regard, NADA verifies the circumstances in which the possible violation of anti-doping regulations was committed and informs the athlete or the person assisting the athlete, the responsible national sports federation, the Ministry of Youth and Sports, the National Olympic Committee, the responsible international sports federation and World Anti-Doping Agency on anti-doping rules and the rights of the athlete or person concerned during the hearing procedure.

As a result of the analysis of biological samples, as a temporary measure, NADA:

$>\quad$ is obliged to temporarily suspend the athlete, based on a positive result for a banned substance, except for specific substances;

$>$ may order the temporary suspension of an athlete on the basis of a positive result for a specific substance or on the basis of another possible infringement of anti-doping rules in the context of a sporting event.

Regardless of whether or not he has been temporarily suspended, the suspected athlete has the right to a hearing in order to defend himself against the charge of anti-doping rules and to present conclusive evidence in his defense. In order to ascertain these facts, NADA establishes a Commission for the hearing of athletes and the assisting staff of athletes, which is guided by the principles of legality, fairness, impartiality and fairness. The examination of the case in the Hearing Commission will not exceed 3 months from the end of the process of managing the results of the biological samples analysis, except the terrific cases or if the Director General of National Anti-Doping Agency decides to organize an emergency hearing procedure. The hearing commission of the athletes and the athletes' assistant staff is obliged to issue in a written, motivated, dated and communicated decision in a reasonable time to the athlete or other persons concerned. Both the decision of the Hearing Commission regarding the athlete or his assistant staff member who violated the anti-doping regulations, and the NADA decisions can be challenged by athletes or other interested persons. Cases concerning national sports events or involving national level athletes can be challenged at the Appeal Commission within NADA, by national level athletes or another person who is the subject of the contested decision, the sports structure to which the athlete belongs or the other party in connection with which the contested decision or WADA was taken.

The Board of Appeal shall examine the case out of court and shall issue a written, reasoned, dated, drafted and communicated decision within a reasonable 
time. The decisions of the Board of Appeal may be challenged at the Court of Sports Arbitration in Lausanne.

On the other hand, cases involving international sporting events or international athletes may be challenged at the Court of Sports Arbitration in Lausanne by international athletes or another person who is the subject of the contested decision, whose sporting structure belongs to the athlete or the other party in connection with whom the contested decision was taken, the responsible international sports federation, the anti-doping organization of the athlete / person's residence country, NADA or WADA.

Given that the athlete may suffer negative moral and patrimonial consequences, as a result of the establishment of the doping control procedure, the confidentiality of data and information must be ensured throughout the process. Thus, the identity of the athletes or their assistants, who are suspected of violating one of the anti-doping regulations, will be made public by NADA only after the final settlement of the case. At the same time, NADA may make public comments on a pending case, if they are necessary in response to public comments from athletes or their assistants. The identity of the athletes or their assistants, who after the final settlement of the case has not been found guilty of one or more violations of anti-doping regulations, may be made public only with their written consent.

\section{Conclusions}

Contemporary sports activity is seen as a complex phenomenon, involving both physical components and a number of medical, legal or economic aspects. Lately, world sport has been marked by heated discussions about doping and its effects. In this context, athletes and members of its team must be aware of the facts that may constitute infringements of anti-doping legislation and the regulations on the procedure for conducting doping control. The acquisition of these legal and medical norms will favor the development of the athlete and will have the effect of preventing the risks posed by the doping phenomenon.

\section{References}

Parlamentul României. (2006, martie 1). Legea nr. 227/2006 privind prevenirea şi combaterea dopajului în sport. Monitorul Oficial, 156. [Parliament of Romania. Law nr. 227/2006 on preventing and combating doping in sport. Official Gazette, 156.] bttp:// Legislatie.just.ro/Public/DetaliiDocumentAfis/190452

Parlamentul României. (2012, iulie 11). Legea nr. 185/2012 cu privire la prevenirea şi combaterea dopajului în sport. Monitorul Oficial 1-5. [Parliament of Romania. Law nr. 185/2012 on preventing and combating doping in sport. Official Gazette 1-5.] http://lex.justice.md/viewdoc.php?id=376744\&lang=1

Guvernul României - Agenția Națională Anti-Doping. (2003). Standardul internațional pentru testare. [Government of Romania - National Anti-Doping Agency. International Standard for Testing] http://www.anad.gov.ro/pdf/ legislatie/i-standard-inttestare.pdf 